\title{
IMPLEMENTASI PLUGIN MATHJAX UNTUK MENAMPILKAN EQUATION INTERAKTIF PADA MEDIA PEMBELAJARAN MATEMATIKA BERBASIS WEB MENGGUNAKAN CMS WORDPRESS
}

\author{
Oleh: \\ Suendri", Nanda Novita** \\ *Dosen Tetap Program Studi Sistem Informasi FST UIN Sumatera Utara Medan \\ ***Dosen Program Studi Sistem Informasi FST UIN Sumatera Utara Medan \\ Jl. IAIN No.1 Medan, Sumatera Utara 20235 \\ Email: $\underline{\text { suendri@uinsu.ac.id, }}$,**ndanovita3@gmail.com
}

\begin{abstract}
:
The development of modern Information Technology has greatly changed the paradigm of the delivery of learning materials to learners, ranging from changes in methods that make teachers no longer as the only source of information to the use of learning media using the internet. One of the Content Management System that has been available for free that is easy to use in the medium of learning via the internet is WordPress. While the plugin used to display Math notation is Mathjax. MathJax is a plugin created by the American Mathematical Society (AMS) and the Society for Industrial and Applied Mathematics (SIAM) aimed at displaying high quality math and scientific notations that can run on all browsers. support for LaTeX, MathML and other equations markup directly in the HTML source. an extensible, modular design with a rich API for easy integration into web applications.
\end{abstract}

\section{Keywords:}

Internet, MathJax, Equation, Learning Media, Math, Wordpress.

\section{A. Pendahuluan}

Pembelajaran berbasis Teknologi Informasi dan Komputer berkaitan dengan segala situasi dimana kegiatan dan bahan pelajaran disampaikan melalui komputer. Introduksi komputer dengan kemampuannya mengola dan menyajikan tayangan multimedia (teks, grafis, gambar, suara, dan movie) memberikan peluang baru untuk mengatasi kelemahan yang tidak dimiliki media elektronik lain seperti siaran radio dan televisi (Darmawijoyo, 2011).Kemajuan Teknologi Informasi sudah banyak dimanfaatkan dalam mendukung kegiatan pembelajaran. Salah satunya adalah pemanfaatan program e-learning sebagai suplemen (bagi kegiatan pembelajaran reguler) maupun sebagai komplemen bagi kegiatan pembelajaran jarak jauh (PJJ) (I Made Tirta, 2014). Ada banyak istilah atau terminologi baru yang muncul dari konsep e-learning mengacu pada kata $e$ learning, seperti virtual learning, online learning, virtual class, e-training, dan web based learning, serta blended learning (Eveline Siregar, 2016). Perkembangan teknologi informasipun kian pesat karena peran internet, melalui 
media internet masyarakat dapat saling terkoneksi bertukar informasi, berkomunikasi serta berbagi sumber daya komputer (Suharno Pawirosumarto, 2012:315). Penggunaan media dalam kegiatan pembelajaran sangat penting, mengingat banyaknya kegunaan media dalam kegiatan pembelajaran, antara lain: (1) memperjelas penyajian pesan agar tidak terlalu bersifat verbalistis; (2) mengatasi keterbatasan ruang, waktu, dan daya indra; (3) mengatasi sikap pasif dari peserta didik. (4) memberikan perangsang, pengalaman dan persepsi yang sama (Sadiman, 2006, pp.17-18).

Matematika adalah salah satu mata pelajaran yang sangat penting dalam dunia pendidikan, karena pelajaran matematika dapat membuat siswa berfikir logis, rasional, kritis dan luas (Astuti, 2017). Pembelajaran matematika di tingkat satuan pendidikan harus dapat menyesuaikan diri dengan perkembangan ilmu pengetahuan dan teknologi yang sedang berlangsung (Depdiknas, 2007: 1).

Dalam penggunaan media pembelajaran matematika berbasis web, salah satu kendala yang dialami oleh pendidik yang ingin memuat materi ajar kedalam media tersebut adalah konten equation atau notasi formula matematika yang tidak bisa dibaca pada halaman browser biasa, rumus-rumus yang kompleks tidak bisa ditampilkan dengan baik. Sehingga konten yang dimuat menjadi tidak sempurna dan sulit untuk dipahami oleh peserta didik. Karena simbol matematika merupakan standar internationalde facto yang termasuk dalam Unicode Character Set, Notasi yaang sering digunakan untuk mendeskripsikan rumus matematika adalah MathML dan LaTex (Michał, Maćkowski dan Piotr Brzoza dkk, 2017). Oleh karena itu, dalam penggunaan media pembelajaran matematika berbasis web diperlukan sebuah pluginyang mampu untuk menampilkan rumus-rumus matematika tersebut menggunakan browser pada umumnya.MathJax dikembangkan sebagai platform untuk matematika di laman web yang berfungsi di semua peramban utama (termasuk perangkat seluler seperti iPad, iPhone, dan Android). Ini memungkinkan penulis untuk menulis persamaan mereka menggunakan beberapa format, termasuk MathML dan TEX, dan ditampilkan hasil menggunakan MathML di browser itu (Davide, Cervone. 2012)

Content Management System (CMS) adalah suatu sistem yang digunakan untuk mengelola dan memfasilitasi proses pembuatan, pembaharuan, dan publikasi konten secara bersama (Collaborative Content Management). Konten mengacu pada informasi dalam bentuk teks, grafik, gambar maupun dalam format-format lain yang perlu dikelola dengan tujuan memudahkan proses pembuatan, pembaharuan, distribusi, pencarian, analisis, dan meningkatkan fleksibilitas untuk ditransformasikan ke dalam bentuk lain (Bitara Risdanto, 2014). Sedangkan wordpress adalah sistem perangkat lunak open source yang banyak digunakan oleh orang diseluruh dunia, untuk membuat website dan blog yang indah. Sistem ini bisa dikustumisasi dengan theme dan plugin (Anthony Hortin. 2012)

\section{B. Metode Penelitian}

Penelitian ini termasuk penelitian pengembangan. Media pembelajaran berbasis web dalam penelitian ini dikembangkan dengan menggunakan langkahlangkah model Borg dan Gall yang dimodifikasi oleh Soenarto (2003), yaitu: analisis produk yang dikembangkan, mengembangkan produk awal, dan uji coba produk. Uji coba produk dalam penelitian ini terdiri dari validasi ahli dan revisi 
Suendri \& Nanda Novita: Implementasi Plugin Mathjax untuk Menampilkan Equation Interaktif pada Media Pembelajaran Matematika Berbasis Web Menggunakan CMS Wordpress

serta uji coba skala kecil dan revisi produk. Uji ahli atau validasi terdiri dari validasi media dan validasi materi yangdilakukan dengan bantuan tiga orang validator, yaitu dosen matematika bergelar doktor, dosen ilmu komputer bergelar magister, dan mahasiswa program studi pendidikan matematika.

\section{Hasil dan Pembahasan}

\section{Analisis Produk yang Dikembangkan}

Analisis produk yang dikembangkan terdiri dari analisis konsep (concept), analisis desain (design), dan pengumpulan bahan (collecting materials). Pada tahap analisis konsep, dilakukan analisis terhadap hal-hal yang diperlukan dalam perencanaan perangkat pembelajaran. Pada tahap ini didapatkan materi yang akan digunakan pada implementasi MathJax adalah notasi atau rumus-rumus yang terdapat pada matakuliah Matematika. Pada tahap analisis desain (design), peneliti membuat rancangan media pembelajaran dari CMS Wordpress dan cara pemasangan plugin Mathjax serta menu-menu yang digunakan, tata letak dan bentuk tampilan hingga sistem berjalan dengan baik. Pada tahap pengumpulan bahan (collecting materials), dilakukan pengumpulan rumus-rumus yang terdapat dalam matakuliah matematika. Pada tahap ini, peneliti mengambil data dari beberapa buku yang diajarkan pada perkuliahan.

\section{Mengembangkan Produk Awal}

Mengembangkan produk awal dimulai dari mengunduh file CMS Wordpress dari website resminya https://wordpress.org. Kemudian plugin MathJax yang telah dikembangkan khusus untuk CMS Wordpress yang tersedia di website wordpress yang beralamat pada https://wordpress.org/plugins/mathjaxlatex. Selanjutnya menentukan nama domain yang akan digunakan saat pemasangan CMS Wordpress yang bisa diakses secara online.

Nama domain yang digunakan pada penelitian ini www.matematikauinsu.xyz, nama ini diambil agar lebih mudah diingat sesuai dengan latar belakang instansi penulis. Nama domain bisa didapatkan dengan cara melakukan sewa domain pada situs-situs penyedia sewa domain. Penyewaan domain bisa dilakukan dengan beragam waktu sewa, mulai dari 3 bulan, 6 bulan, 1 tahun hingga 2 tahun. Selain dari sewa domain juga diperlukan sewa hosting untuk menyimpan atau meletakkan file CMS Wordpress yang kita download sebelumnya. Kapasitas hosting juga beragam, tergantung paket yang disedikan oleh situs penyedia. Langkah selanjutnya adalah upload CMS dan pemasangan sistem seperti pada gambar 1 berikut ini. 


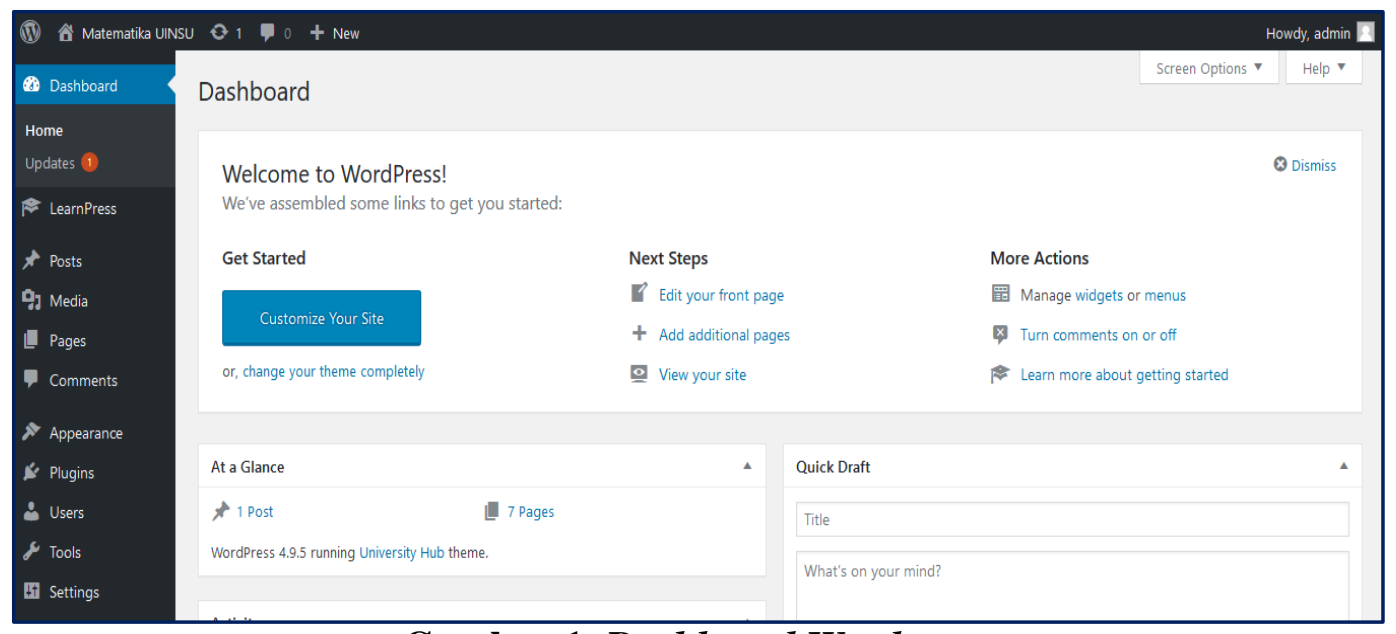

Gambar 1. Dashboard Wordpress

Berikutnya dilakukan pemilihan template yang cocok untuk media pembelajaran, up to date dan responsive jika dikunjungi dari web browser yang berbeda-beda. Setelah template dipasang, berikut hasil tampilan halaman depan pada gambar 2.

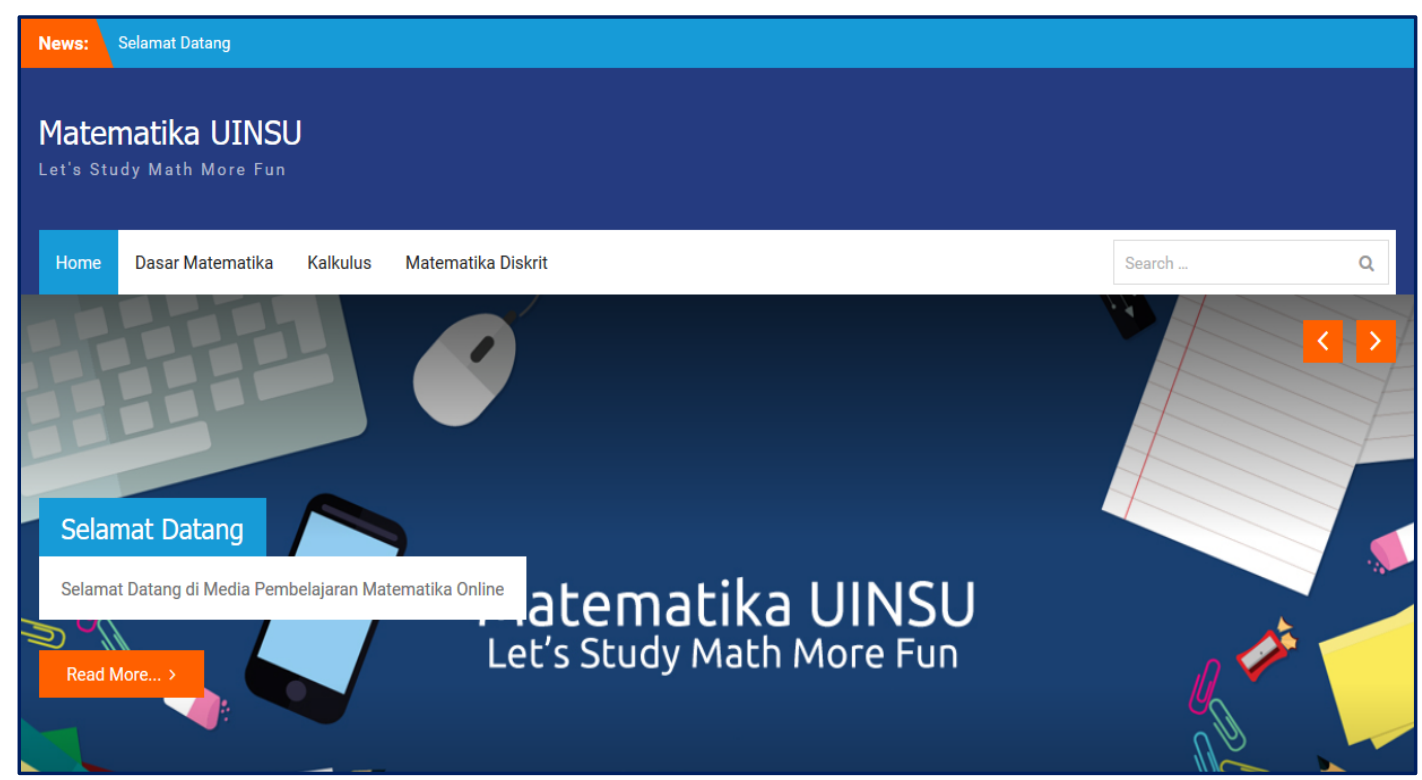

Gambar 2. Halaman Depan

Tidak ada aturan khusus tata tetak menu pada halaman sebuah website, namun jika ditempatkan pada halaman depan, mudah dilihat dan sesuai dengan topik akan menambah kesempurnaan sebuah sistem. Penulis membuat menu utama dibawah judul website dan menambahkan gambar yang bisa bertukar secara otomatis dibawahnya.

Mathjax sudah tersedia dalam bentuk plugin yang siap untuk dipasang pada CMS Wordpress, melalui menu pemasangan dari halaman Dashboard, MathJax secara otomatis siap juga untuk digunakan seperti pada kode di bawah ini: 
Suendri \& Nanda Novita: Implementasi Plugin Mathjax untuk Menampilkan Equation Interaktif pada Media Pembelajaran Matematika Berbasis Web Menggunakan CMS Wordpress
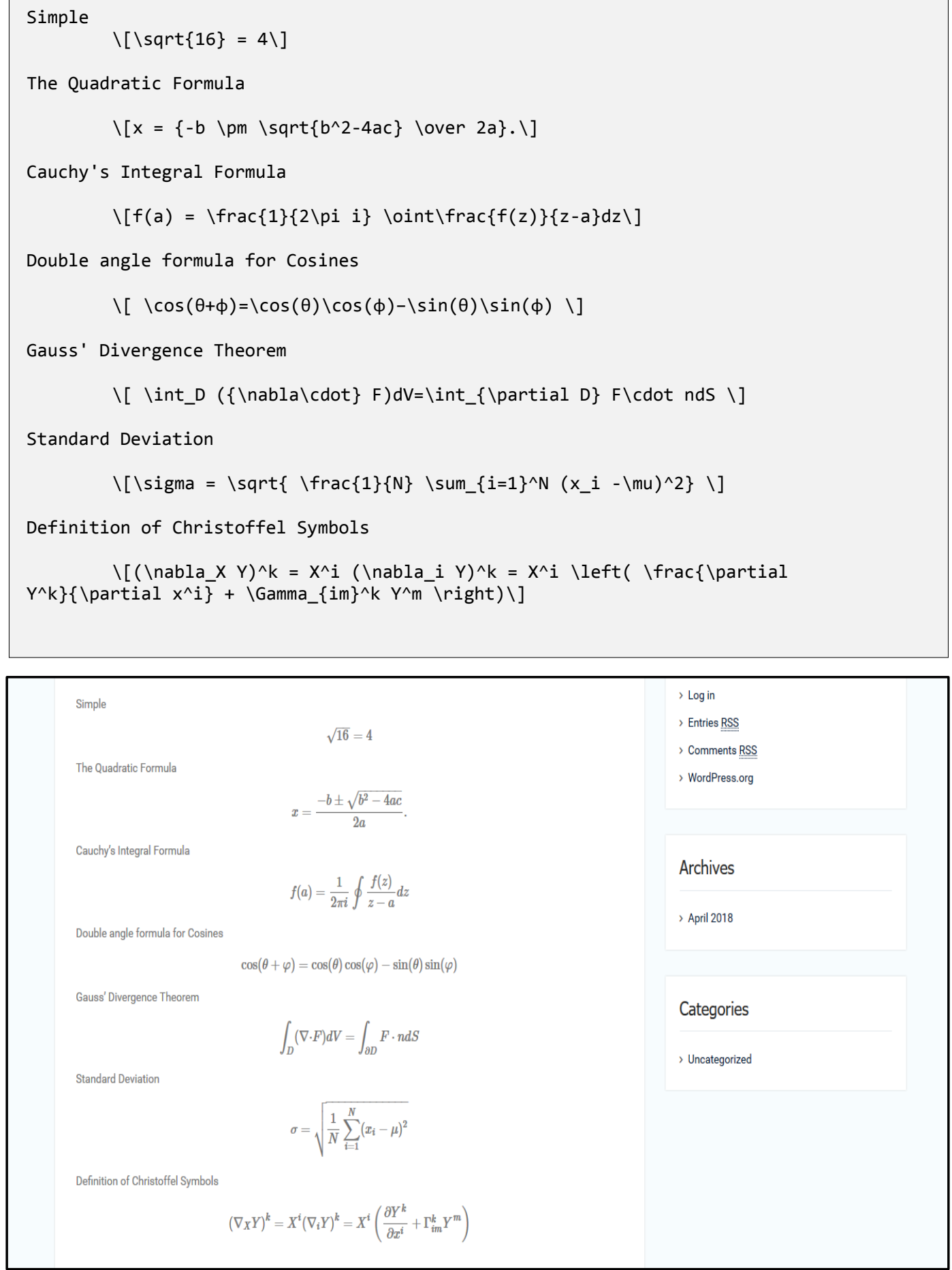

\section{Gambar 3 Notasi Matematika}

\section{Uji Coba Produk}

Setelah produk awal selesai dikembangkan, dilakukan uji coba yang terdiri dari dua tahap, yaitu uji ahli dan uji coba skala kecil. Uji ahli atau validasi terdiri dari validasi media dan validasi materi. Hasil penilaian validator media terhadap plugin dapat dilihat pada tabel 1 berikut. 
Tabel 1. Hasil Validasi Plugin

\begin{tabular}{|c|l|c|}
\hline No. & \multicolumn{1}{|c|}{ Kriteria yang Dinilai } & Skor Rata-Rata \\
\hline 1 & Ketersediaan shorcode & 3 \\
\hline 2 & Kemudahan penggunaan & 2 \\
\hline 3 & Kesesuaian dengan materi ajar & 4 \\
\hline 4 & Kesesuai hasil tampilan & 4 \\
\hline 5 & Kecocokan dengan Browser & 3 \\
\hline \multicolumn{2}{|c|}{ Skor Kevalidan } & $\mathbf{3 , 2}$ \\
\hline
\end{tabular}

Berdasarkan tabel 1 dapat diketahui bahwa skor kevalidan (Va) yang diperoleh sebesar 3,2. Skor ini menunjukkan bahwa plugin yang dipasang pada CMS Wordpress ini dapat dikatakan valid.

Selanjutnya dilakukan uji Ahli Media, pada tahap ini diadakan validasi terhadap kebutuhan sistem sebagai media pembelajaran matematika. Antara lain menu yang digunakan, kesesuaian dengan materi matematika serta kalimat dan kata-kata yang digunakan pada sistem. Hasil penilaian terlihat pada tabel 2 berikut ini.

Tabel 2. Hasil Validasi Media

\begin{tabular}{|c|l|c|}
\hline No. & \multicolumn{1}{|c|}{ Kriteria yang Dinilai } & Skor Rata-Rata \\
\hline 1 & Ketersediaan menu & 4 \\
\hline 2 & Kemudahan penggunaan & 4 \\
\hline 3 & Kesesuaian dengan materi ajar & 3 \\
\hline 4 & Keefektifan kalimat & 3 \\
\hline 5 & Kelengkapan informasi yang dibutuhkan & 3 \\
\hline \multicolumn{2}{|c|}{ Skor Kevalidan } & $\mathbf{3 , 4}$ \\
\hline
\end{tabular}

Langkah terakhir dilakukan uji coba skala kecil, dimana penilaian didapatkan berdasarkan respon mahasiswa terhadap media yang telah dikembangkan. Pada uji coba ini mahasiswa diberikan angket dan meminta mahasiswa untuk mengujungi website yang telah dikembangkan dan memberikan penilaian. Dari hasil respon yang telah diberikan oleh mahasiswa dapat dilihat pada tabel 3 berikut ini:

Tabel 3. Hasil Uji Coba

\begin{tabular}{|l|l|c|}
\hline No & \multicolumn{1}{|c|}{ Kriteria yang Dinilai } & Skor Rata-Rata \\
\hline 1 & Tampilan, warna dan gambar menarik & 3,1 \\
\hline 2 & Kemudahan penggunaan & 3,2 \\
\hline 3 & Kesesuaian dengan materi ajar & 3,1 \\
\hline 4 & Kejelasan notasi yang ditampilkan & 3,5 \\
\hline \multicolumn{2}{|c|}{ Skor Kevalidan } & $\mathbf{3 , 2}$ \\
\hline
\end{tabular}

\section{Pembahasan}

Setelah dilakukan validasi dan uji coba, dapat diketahui bahwa media pembelajaran matematika menggunakan CMS wordpress dengan pluginMathjax tersebut telah berjalan dengan baik dan dapat menampilkan equation atau notasi matematika sebagaimana mestinya. Validasi ahli media menunjukkan bahwa skor rata-rata yang diperoleh adalah $\geq 3$ untuk setiap aspek yang dinilai. 
Suendri \& Nanda Novita: Implementasi Plugin Mathjax untuk Menampilkan Equation Interaktif pada Media Pembelajaran Matematika Berbasis Web Menggunakan CMS Wordpress

Hasil uji coba skala kecil menunjukkan, mahasiswa dengan mudah untuk membaca notasi matematika karena tersusun sebagaimana mestinya sebuah notasi. Letak setiap variabel atau simbol yang digunakan dalam notasi ditampilkan dengan tampilan yang jelas.

Namun Media pembelajaran yang dikembangkan ini masih tetap mempunyai kekurangan, yaitu: 1) Butuh ketelitian untuk membuat equation matematika, karena shortcode yang disediakan masih dalam bentuk kode yang secara sekilas sulit dipahami. 2) Butuh banyak waktu untuk membuat equation tersebut, tidak tersedianya form khusus menjadikan notasi dibuat dalam waktu yang lama.

\section{Kesimpulan}

Dalam penggunaan media pembelajaran matematika berbasis web, salah satu kendala yang dialami oleh pendidik yang ingin memuat materi ajar kedalam media tersebut adalah konten equation atau notasi formula matematika yang tidak bisa dibaca pada halaman browser biasa. Dengan menggunakan plugin Mathjaxyang telah diuji coba pada penelitian ini, dapat disimpulkan bahwa plugin tersebut sangat membantu untuk menampilkan berbagai notasi matematika hingga yang rumit dan panjang sekalipun. Plugin ini juga didukung berbagai web browser sehingga peserta didik tidak mesti menggunakan web browser khusus. Kedepan, penelitian ini diharapkan terus dikembangkan dengan membuat form input khusus untuk plugin Mathjax sehingga memperkecil kekurangan yang terdapat pada plugin ini.

\section{DAFTAR PUSTAKA}

Astuti dan Nurhidayah Sari. 2017. Pengembangan Lembar Kerja Siswa (LKS) Pada Mata Pelajaran Matematika Siswa Kelas X SMA. Bangkinang: Journal Cendekia: Jurnal Pendidikan Matematika, Volume 1, No. 2, November 2017.

Cervone, Davide. 2012. MathJax: A Platform for Mathematics on the Web. New York: Notices of the American Mathematical Society, Vol.59 No.2.

Darmawijoyo. 2011. Pembelajaran Matematika Berbasis Web. Palembang: Jurnal Sistem Informasi, Vol.3 No.1.

Depdiknas. 2007. Kajian Kebijakan Kurikulum Mata Pelajaran Matematika. Jakarta: Badan Penelitian dan Pengembangan Pusat Kurikulum.

Michał, Maćkowski dan Piotr Brzozal dkk. 2017. Multimedia Platform for Mathematics' Interactive Learning Accessible to Blind People. Gliwice: Dominik Spinczyk Multimedia Tools and Applications, Vol.77 No.288, DOI: http://dx.doi.org/10.1007/s11042-017-4526-Z

Pawirosumarto, Suharno. 2012. Aplikasi Komputer. Jakarta: Mitra Wacana Media. 
Risdanto, Bitara. 2014. Pengembangan e-learning Berbasis Web Menggunakan CMS (Content Management System) Wordpress di SMA Negeri 1 Kota Magelang. Magelang: Program Studi Pendidikan Teknik Informatika Fakultas Teknik Universitas Negeri Yogyakarta.

Sadiman, A.S, dkk. 2006. Media Pendidikan: Pengertian, Pengembangan, dan Pemanfaatannya. Jakarta: Pustekkom Diknas \& Raja Grafindo Perkasa.

Setyadi, Danang dan Abd. Qohar. 2017. Pengembangan Media Pembelajaran Matematika Berbasis Web pada Materi Barisan dan Deret. Semarang: Kreano Jurnal Matematika Kreatif - Inovatif, Vol.8 No.1, DOI: http://dx.doi.org/10.15294/kreano. v8i2.5964

Siregar, Eveline. 2016. Pelembagaan Web-Based Learning pada Jurusan Kurikulum dan Teknologi Pendidikan Fakultas Ilmu Pendidikan Universitas Negeri Jakarta. Yogyakarta: Jurnal Inovasi Teknologi Pendidikan Volume 3, No 1, April 2016.

Tirta, I Made. 2014. Pengembangan E-Modul Statistika Terintegrasi dan Dinamik dengan R-shiny dan Mathjax. Jember: Prosiding Seminar Nasional Matematika, Universitas Jember, 19 November 2014. 